\title{
31. EFFECT OF HYDROSTATIC PRESSURE ON THE THERMAL CONDUCTIVITY OF BASALT FROM HOLE 504B, WITH SOME REASSESSMENT OF THE SHIPBOARD DATA ${ }^{1}$
}

\author{
Hajimu Kinoshita, ${ }^{2}$ Hideyuki Fujisawa, ${ }^{3}$ Naoki Sakai, ${ }^{3}$ Hiroki Sato, ${ }^{4}$ and Hiroshi Watanabe ${ }^{5}$
}

\begin{abstract}
Thermal properties (diffusivity and heat capacity) at varying temperatures up to $200^{\circ} \mathrm{C}$ and the thermal diffusivity under hydrostatic pressures up to $1 \mathrm{GPa}$ at room temperature were measured on two basaltic samples recovered from Hole 504B drilled during Ocean Drilling Program Leg 148. Rock fabrics and porosity are key factors controlling the thermal properties of these rock samples. Estimates of thermal conductivities of rocks in situ can be made on the present results. The estimated values can be compared with those obtained by shipboard measurements, enabling us to eliminate incorrect data. The shipboard measurements of rock samples containing a small amount of water-filled pores give reliable thermal conductivity values. The validity of measuring wet samples also is verified by thermal diffusivities of dried core samples, measured experimentally under hydrostatic pressures.
\end{abstract}

\section{INTRODUCTION}

Thermal conductivity data are available from the top to the bottom of Hole 504B. These samples penetrate through the sedimentary layer down to the Layer 2/3 (basalt/gabbro) boundary. Heat-flow values and lithospheric thickness help to constrain the formation age of the oceanic basin to as old as $80-120 \mathrm{Ma}$. Heat-flow values can be obtained by combining the subseafloor temperature gradient with the in situ thermal conductivity. The thermal conductivity usually is obtained by measuring samples on board at laboratory temperature and atmospheric pressure. Depressurization of rock samples deep from the basement increases the volume of pores in each sample, which may have a large effect on the thermal conductivity values. This study clarifies experimentally the influence of porosity on the thermal properties (diffusivity, heat capacity, and conductivity) in order to obtain intrinsic (or rock matrix) thermal conductivity by applying the formulae of Walsh and Decker (1966), by which the matrix conductivity is obtained by extrapolating values at high pressure to zero pressure conditions. If this is applicable, the experimental difficulty for measuring the conductivity of small and irregularly shaped hard rock samples will be significantly diminished.

Another goal of this study was to determine whether hydrostatic pressue significantly affects the intrinsic matrix thermal conductivity. If it does, heat-flow data obtained by conventional methods must be corrected both for porosity and for the pressure dependence of matrix conductivity. Pressure measurements in the present experiment were made from atmospheric pressure to $1 \mathrm{GPa}$.

\section{METHODS}

Samples measured in this study were cut into cylinders $5.0 \mathrm{~mm}$ in diameter and $10.0 \mathrm{~mm}$ in length (for thermal expansion in vacuum),

'Alt, J.C., Kinoshita, H., Stokking, L.B., and Michael, P.J. (Eds.), 1996. Proc. ODP, Sci. Results, 148: College Station, TX (Ocean Drilling Program).

2Japan Marine Science and Technology Center, Headquarters, 2-15 NatsushimaCho, Yokosuka 237 Japan. jimmy@jamstec.go.jp

${ }^{3}$ Earthquake Research Institute, University of Tokyo, 1-1-1 Yayoi, Bunko-ku, Tokyo, 113 Japan.

${ }^{4}$ Institute for Study of the Earth's Interior, Okayama University, 827 Yamada, Misasa, Tottori, 682 Japan.

'Faculty of General Education, Osaka Sangyo University, 3-1-1 Nakakakiuchi, Daito-shi, Osaka, 574 Japan.
$10.0 \mathrm{~mm}$ in diameter and $20.0 \mathrm{~mm}$ in length (for thermal diffusion under pressure), or into disks $10.0 \mathrm{~mm}$ in diameter and $2.5 \mathrm{~mm}$ in thickness (for heat capacity and thermal diffusivity in vacuum). Thermal expansion results are not reported in this article. Both ends of the samples were polished using alumina powder of 600 mesh (the grain size of phenocrysts is far smaller than $2.5 \mathrm{~mm}$.). The samples were dried in a furnace at $100^{\circ}-110^{\circ} \mathrm{C}$ for a couple of days. The disk samples were used for measuring heat capacity, thermal diffusivity, density, and porosity. All measurements were made at room temperature $\left(15^{\circ}-20^{\circ} \mathrm{C}\right)$. Heat capacity and diffusivity was measured using the flash method (e.g., Watanabe, 1992) in vacuum of $10^{-3}$ Torr. $(0.132$ $\mathrm{Pa}$ ). Density (dry-bulk density) and porosity were obtained by comparing the weights of dried and water saturated samples on a highsensitivity balance open to laboratory air. Saturation by water was made by placing the sample in a hydraulic pressure of $1 \mathrm{GPa}$, which is high enough to close pores (granite sample, Walsh and Decker, 1966). The problem is briefly referred to in the footnote of Table 1.

Thermal diffusivity was measured by placing a heater wire in the center and two thermocouples 3 and $4 \mathrm{~mm}$ off center of the cylindrical sample. The basic idea of the present method is similar to the Angstrom method (e.g., Carslaw and Jaeger, 1959, p. 136; Watanabe, 1992) for a transient heat transfer. If the sample assembly has a good cylindrical symmetry, a probe method also can be applied (Carslaw and Jaeger, 1959). As noted later in this paper, we tried both methods and obtained data consistent with other measurements only by the latter method. Instead of drilling a thin hole in the cylindrical core sample $(10.0 \mathrm{~mm}$ in diameter and $20.0 \mathrm{~mm}$ in length $)$, thin slits $(0.50 \mathrm{~mm})$ were cut into the cylinder. After placing the heater wire $(0.1-\mathrm{mm}$ nickel-chromium steel wire) and platinum-13\%rhodium thermocouple $(0.1-\mathrm{mm}$ wire), the slits were closed by gluing in thin plates cut from the original sample. The sample assembly, including the thermocouples and heater wire, was coated with silicone rubber to prevent penetration of pressure fluid during the experiment (Fig. 1). The whole sample assembly is compressed in a cylindrical vessel that creates hydrostatic pressures up to $1 \mathrm{GPa}$. The heater wire and thermocouple were connected to an electronic circuit controlled by a microcomputer (CPU) through a general purpose interface board (GPIB; Fig. 2 adapted from Kinoshita, 1992).

Thermal diffusivity of the sample under pressure is obtained by applying a steady state heat-flow formula of a cylindrical symmetry ( $\$ 7.2-\mathrm{V}$, Carslaw and Jaeger, 1959). A transient thermal transmission technique (formula 2.5.21, Beck et al., 1985) may be useful, but the latter method gave unrealistic values from our present experiment. The thermal conductivity is calculated on an assumption that the den- 


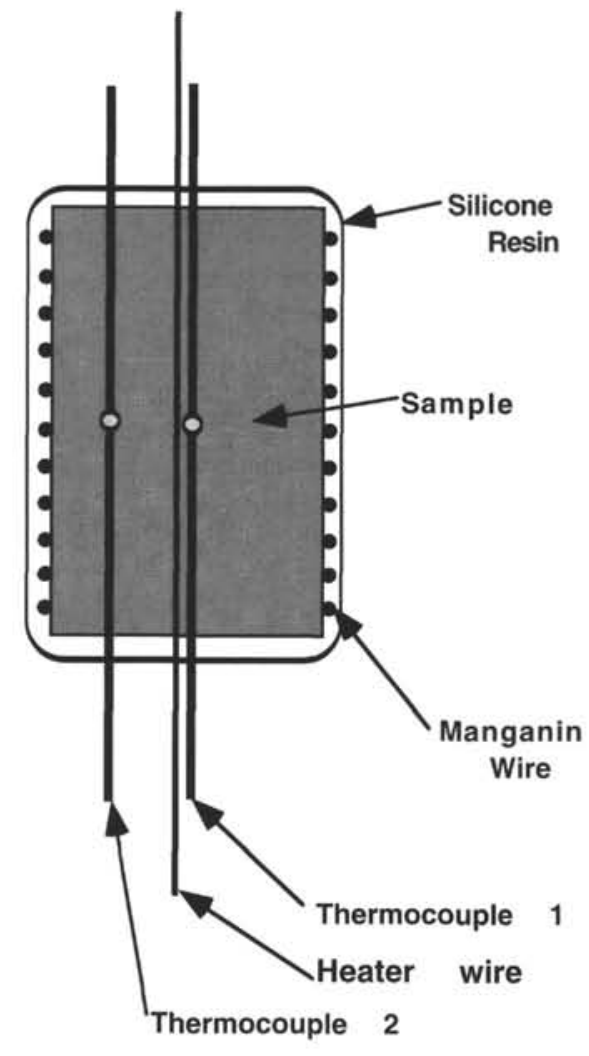

Figure 1. Sample block: a cylindrical rock piece, a pair of thermocouples, heater wire, manganin wire pressure gage, and silicone coating covering entire assembly.

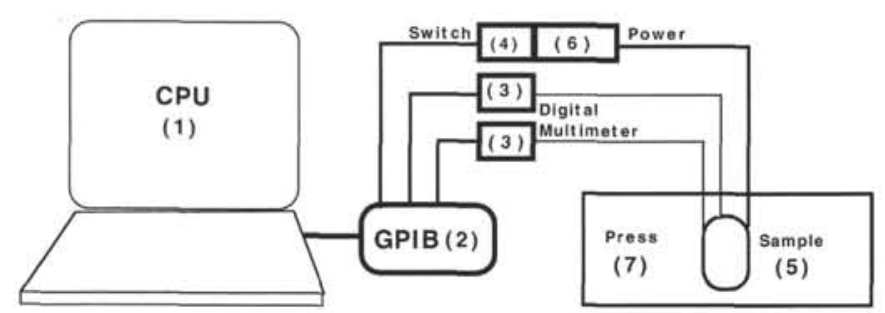

Figure 2. A schematic view of the measuring system. Desk-top computer (1) controls data acquisition ( $2=$ GPIB interface) from digital multimeter ( 3 ) connected to the thermocouple(s) in the sample (5) in a hydraulic press (7). Electric power (6) to the heater in the sample is also activated by the computer $(4=$ switch interface $)$.

sity and specific heat of the sample do not change significantly in the present pressure range. Although a correction to the density change of the sample under pressure may be estimated from the sonicvelocity data under pressures that will be presented elsewhere in this volume, it is not intended in the present interpretation.

\section{RESULTS}

The thermal conductivity of each sample (Table 1) in vacuum (approximaely $0.1 \mathrm{~Pa}$ ) was obtained by measuring heat capacity and thermal diffusivity as shown in Figure 3. The thermal conductivity of dry samples evidently is influenced by porosity. The influence of the porosity is twofold: (1) from the insulation caused by void spaces that
Table 1. Thermal parameters of two samples from Hole 504B.

\begin{tabular}{cccccc}
\hline $\begin{array}{c}\text { Core/section, } \\
\text { interval }(\mathrm{cm})\end{array}$ & $\begin{array}{c}\text { Depth } \\
(\mathrm{mbsf})\end{array}$ & $\begin{array}{c}\text { Specific } \\
\text { heat } \\
(\mathrm{kJ} /[\mathrm{kg} \cdot \mathrm{K}])\end{array}$ & $\begin{array}{c}\text { Thermal } \\
\text { diffusivity } \\
\left(10^{-7} \mathrm{~m}^{2} / \mathrm{s}\right)\end{array}$ & $\begin{array}{c}\text { Bulk } \\
\text { density } \\
\left(\mathrm{g} / \mathrm{cm}^{3}\right)\end{array}$ & $\begin{array}{c}\text { Thermal } \\
\text { conductivity } \\
(\mathrm{W} /[\mathrm{m} \cdot \mathrm{K}])\end{array}$ \\
\hline 148-504B- & & & & & \\
24IR-1.99-101 & 2017.5 & 0.7 & 6.25 & 3.11 & 1.26 \\
250R-1.0-8 & 2080.4 & 0.7 & 7.0 & 3.08 & 1.45 \\
Zero-pressure-extrapolation: & & & $1.91(0.38)^{*}$ & \\
\hline
\end{tabular}

Notes: Specific heat at room temperature $\left(25^{\circ} \mathrm{C}\right)$ in vacuum, $\sim 1.33 \mathrm{~Pa}$. Asterisk $\left(^{*}\right)=$ experimental error (in parentheses) from scattering of raw data points. Porosity $(1.45 \%)$ for both samples decreases the matrix thermal conductivity by $3.7 \%-30 \%$ using either one of the models of Walsh and Decker (1966).

usually are filled by air even after evacuation during the measurements, and (2) from the different matrix and air conductivity. It is hard to estimate the amount of air remaining in the sample that has been placed in a vacuum at around room temperature to $200^{\circ} \mathrm{C}$. In the present interpretation, therefore, the pressure of air trapped in the interstitial pore is, assumed to be about $1 \mathrm{~atm}\left(1.013 \times 10^{5} \mathrm{~Pa}\right)$, which may overestimate the bulk conductivity by about a few percent according to the formulae of Walsh and Decker (1966). The matrix conductivity of the two samples is given in Table 1, which was deduced from the heat capacity, porosity, and density data. The effect of porosity on the thermal conductivity is described in Table 1.

The thermal diffusivity of the sample under pressure is measured using a method similar to the needle-probe method (Jaeger, 1958). Briefly, the change of the probe temperature, after switching on the electric current to the heater wire in the sample, is recorded once each second for about $20 \mathrm{~s}$ by a digital multimeter connected to the controlling computer. The measurement duration $(20 \mathrm{~s})$ is limited by the sample size. The temperature of the sample increases gradually because of the heat produced in the center of the sample. The increase in the sample temperature might cause physicochemical changes, which result in the change in the thermal conductivity of the sample. However, this is unlikely to occur because the heater wire generates only $0.9 \mathrm{~W} / \mathrm{cm}$ (total $1.8 \mathrm{~W}$ ) for $20 \mathrm{~s}$, raising the temperature of the samples no more than a few degrees.

Pressures exerted on the specimens ranged from 0 to $1 \mathrm{GPa}$, from which the thermal diffusivity (converted to conductivity) of the matrix at $80 \mathrm{MPa}$ (equivalent to pressure of $2000 \mathrm{mbsf}$ at Site 504) is estimated by extrapolating high-pressure values to $80 \mathrm{MPa}$. The pressure on the sample is increased in discrete 100-MPa steps, and the best fit to the discrete data point is used to extrapolate intrinsic zeropressure value(s) (Fig. 4). The zero pressure values of the samples are given in Table 1 along with other basic thermal parameters.

\section{DISCUSSION}

It is possible to calculate the thermal conductivity values from porosity data of rocks saturated with seawater when the porosity is not large. It is shown after Walsh and Decker (1966) that the porosity of isolated voids $(5 \%-10 \%)$ decreases the thermal conductivity of the sample by $7 \%$ to $13 \%$, assuming the pores are saturated with seawater. Data of Hole 504B rock samples are classified into three groups (Fig. 5). One group belongs to the depth interval of 270 to 800 mbsf. A second group is from 800 to $1000 \mathrm{mbsf}$, which shows a rapid increase of thermal conductivity with depth. The third group is from below 1000 mbsf to the bottom of the hole. The data set from 1600 mbsf to 2000 mbsf was discarded (not plotted in Fig. 5) because we have found that much of the data from this section apparently contains a certain amount of error.

Statistical calculation of the data from two groups (the shallower part and bottom layer, skipping the second group) shows that the thermal conductivity of the matrix (basaltic material) of this site is 2.3 

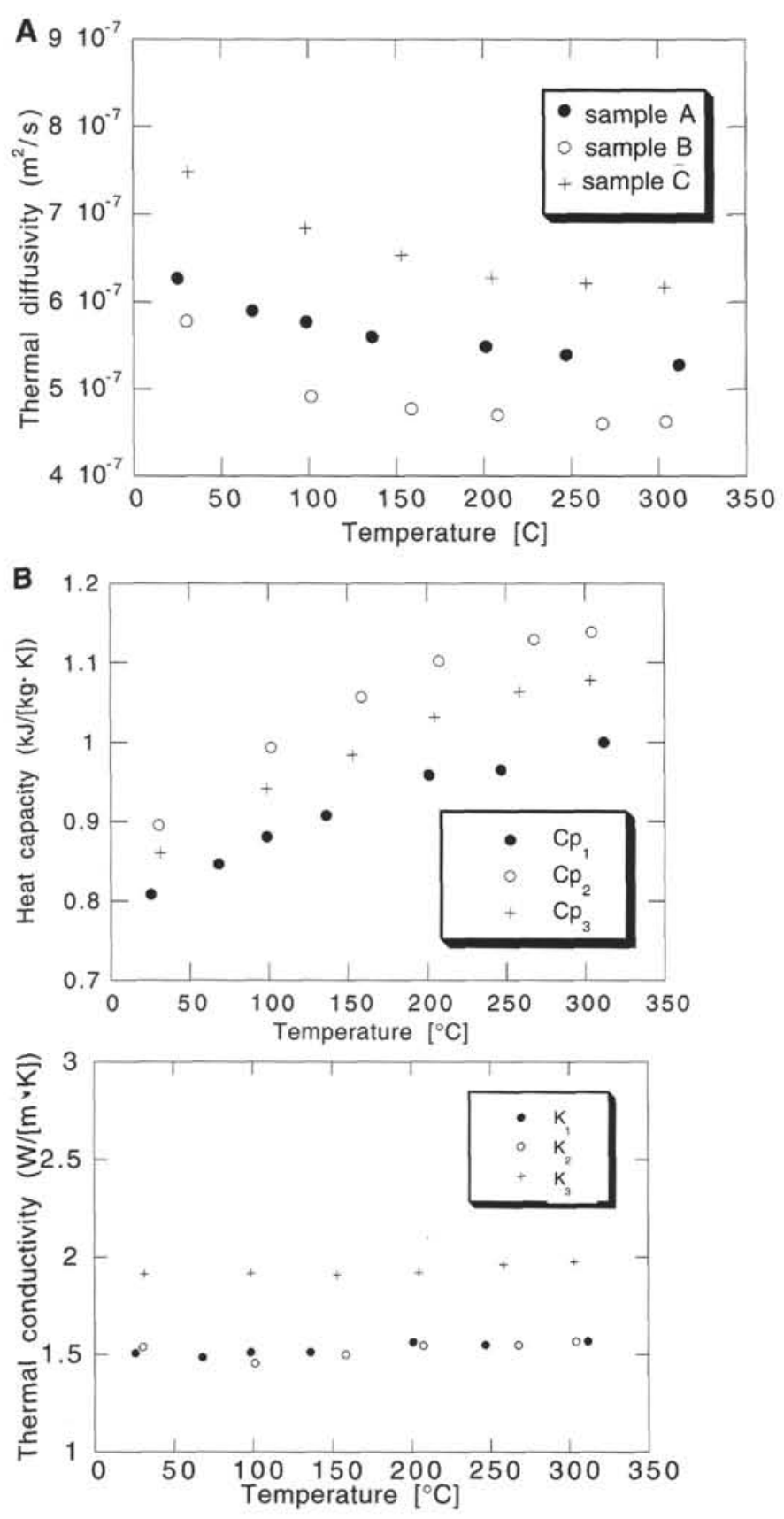

Figure 3. Variations in temperature vs. (A) thermal diffusivity $\left(\mathrm{m}^{2} / \mathrm{s}\right),($ B) heat capacity $(\mathrm{kJ} /[\mathrm{kg} \cdot \mathrm{K}])$, and $(\mathbf{C})$ resultant thermal conductivity $(\mathrm{W} /[\mathrm{m} \cdot \mathrm{K}])$. Samples used are 148-504B-241R-1, 99-101 cm (Piece 19), and 250R-1, 0$8 \mathrm{~cm}$ (Piece 1). Abbreviations are as follows: alphabetical letters a, Cp, and $\mathrm{K}$ stand for thermal diffusivity, specific heat, and thermal conductivity, respectively. Subscripts 1 and 2 correspond to samples in Table 1 ( $1=$ upper raw scores, 2 lower raw scores), and subscript 3 is Sample 148-504B274R-1, 18-26 cm. with a standard deviation of $0.4 \mathrm{~W} /(\mathrm{m} \cdot \mathrm{K})$, which is comparable to the value obtained by Kawada (1964) although the author did not describe porosity of the basaltic sample.

Present results show that the pressure effect on the thermal conductivity is twofold. First, pores close under relatively lower pressure (less than $100 \mathrm{MPa}$; Walsh and Becker, 1966). Second, the intrinsic conductivity of the matrix material gradually increases. It is clear that the water-saturated sample for shipboard measurements gives a conductivity value close enough to the probable intrinsic conductivity values given by extrapolating conductivity values to zero pressure (bottom line of Table 1).

This discussion may not apply to the sediment samples with large porosity $(40 \%-70 \%)$ in the upper part of Hole 504B because the connection of the porosity network and the main composition of the matrix are completely different from that in the basement rocks. It is striking, however, that the water-saturated sediment sample shows fairly uniform thermal conductivity and is insensitive to hydrostatic pressure as shown, for instance, by Wilkens and Langseth (1983) and Kinoshita (1992).

\section{ACKNOWLEDGMENT}

The authors are obliged to Pr. E. Ito, Institute for Study of the Earth's Interior, Okayama University, for his suggestions on sample measurement techniques under hydrostatic pressures.

\section{REFERENCES}

Beck, J.V., Blackwell, B., and St. Clair, C.R., 1985. Inverse Heat Conduction: An Ill-posed Problem: New York (Wiley-Interscience).

Carslaw, H.S., and Jaeger, J.C., 1959. Conduction of Heat in Solids (2nd ed.): Oxford (Clarendon Press).

Jaeger, J.C., 1958. The measurement of thermal conductivity and diffusivity with cylindrical probes. Eos, 9:708-710.

Kawada, K., 1964. Studies of the thermal state of the Earth, 15: variation of thermal conductivity of rocks. Bull. Earthquake Res. Inst., Univ. Tokyo, 42:631-647.

Kinoshita, H., 1992. Effect of hydrostatic pressure on the thermal conductivity of suboceanic materials recovered during Leg 128, Japan Sea. In Tamaki, K., Suyehiro, K., Allan, J., McWilliams, M., et al., Proc. ODP, Sci. Results, $127 / 128$ (Pt. 2): College Station, TX (Ocean Drilling Program), 1017-1019.

Walsh, J.B., and Decker, E.R., 1966. Effect of pressure and saturating fluid on the thermal conductivity of compact rock. J. Geophys. Res., 71:30533061.

Watanabe, H., 1992. Thermal constants for $\mathrm{Ni}, \mathrm{NiO}, \mathrm{MgO}$ and $\mathrm{CoO}$ at low temperatures. Thermomechanics, 218:365-372.

Wilkens, R.H., and Langseth, M.G., 1983. Physical properties of sediments of the Costa Rica Rift, Deep Sea Drilling Project Sites 504 and 505. In Cann, J.R., Langseth, M.G., Honnorez, J., Von Herzen, R.P., et al., Init. Repts. DSDP, 69: Washington (U.S. Govt. Printing Office), 659-673.

Date of initial receipt: 19 August 1994

Date of acceptance: 23 January 1995

Ms 148SR-144 

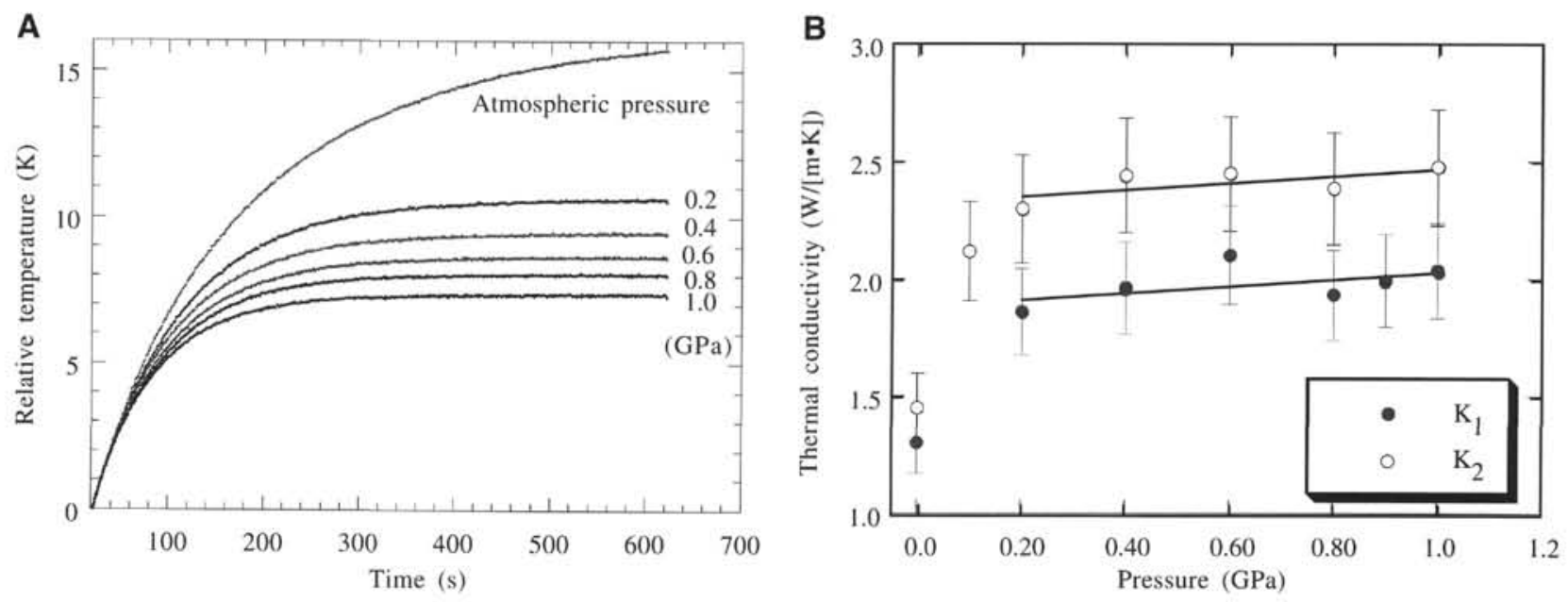

Figure 4. A. An example of temperature change over time of sample a, (see Fig. 3) at $3 \mathrm{~mm}$ off center of the sample cylinder. Pressure values attached to each curve. B. Change in thermal conductivity $(\mathrm{W} /[\mathrm{m} \cdot \mathrm{K}])$ vs. pressure up to $1 \mathrm{GPa}$ for sample $\mathrm{a}_{1}$ (for $\mathrm{a}_{1}$ see Fig. 3 ).

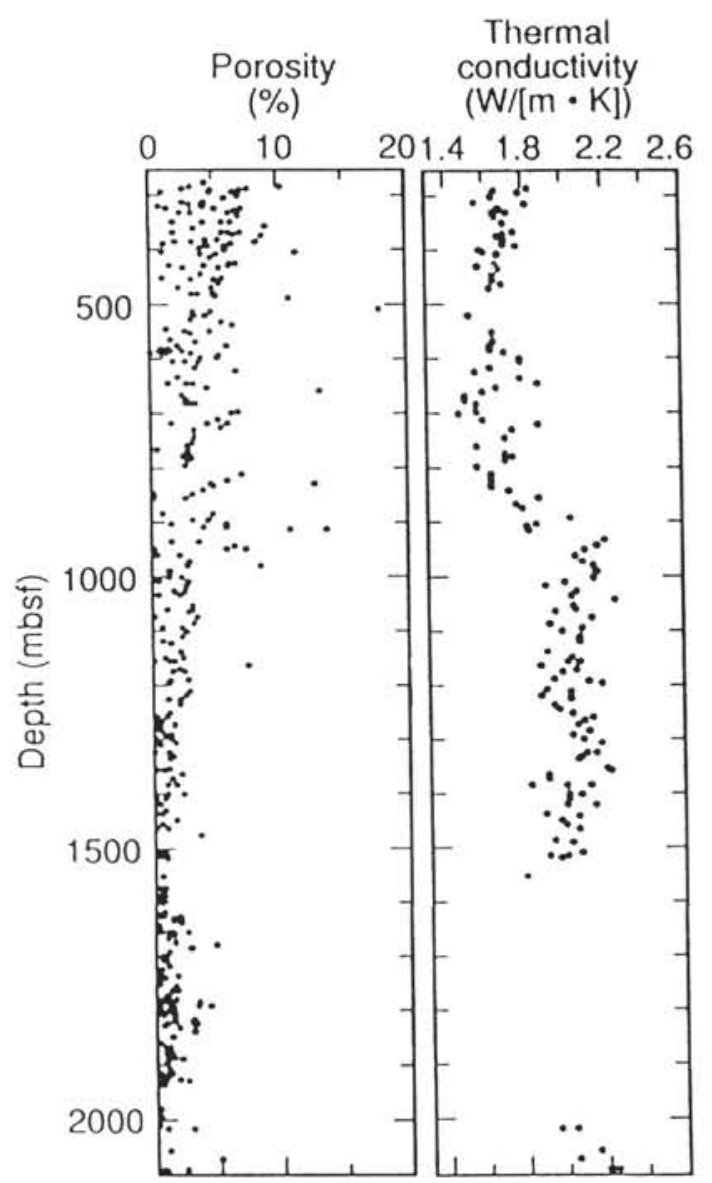

Figure 5. The downhole porosity and thermal conductivity distribution obtained from individual core samples from Hole 504B. Only sections of the rock formation are shown. Data set from $\sim 1600$ to 2000 mbsf is entirely discarded for the reason given in the text. 